\title{
Politicas internacionais em ciência e saúde: a pesquisa celular e a medicina regenerativa
}

\section{| ${ }^{1}$ Liliana Acero |}

Resumo: O desenvolvimento de medicamentos e terapias baseados nos princípios científicos das biociências e das biotecnologias da saúde - com base em células vivas e difíceis de serem estandardizadas tem sido um tema de amplos debates públicos em nível global. A área tem sido recentemente demarcada como medicina regenerativa, que inclui as pesquisas e terapias com células-tronco (PCT e TC), foco deste estudo.

No presente artigo, apresentam-se os principais eventos históricos na área de pesquisa celular, descreve-se o estágio atual na evolução da medicina regenerativa e as características das principais políticas desenvolvidas, em especial pelos países de liderança global, e em relação à regulamentação dos direitos de propriedade intelectual. Desenvolve-se análise quantitativa e qualitativa com dados secundários coletados em nível internacional, revisão bibliográfica e de informações em arquivos das instituições de regulamentação globais, resenhas jornalísticas atualizadas, assim como de artigos especializados publicados em revistas internacionais. A revisão da informação é guiada pelas seguintes perguntas: quais são as trajetórias principais de inovação em ciência e saúde nessa área? Quais fatores incidem principalmente na sua evolução? Conclui-se com reflexões específicas sobre os impactos dos desenvolvimentos associados na Saúde Coletiva.

> Palavras-chave: medicina regenerativa; pesquisas e terapia com células-tronco; Saúde Coletiva; política pública em saúde; direitos de propriedade intelectual.
1 Instituto de Economia,

Universidade Federal do Rio de Janeiro. Rio de Janeiro-RJ,

Brasil. Endereço eletrônico:

lilianaacero2009@gmail.com 
O desenvolvimento de medicamentos e terapias baseados nos princípios científicos das biociências e das biotecnologias da saúde - com base em células vivas e difíceis de serem estandardizadas - tem sido um tema de amplos debates públicos em nível global, que se intensificaram a partir da clonagem da ovelha Dolly, em 1997, pelo Professor Ian Wilmut, do Instituto Roslinem Edimburgo (ACERO, 2011a). A área tem sido recentemente definida como de medicina regenerativa, que inclui as pesquisas e terapias com células-tronco (PCT e TC), foco deste estudo.

$\mathrm{O}$ artigo apresenta um panorama atualizado das tendências científicas, econômicas e sociais no cenário global e dos principais eventos históricos da PCT e TC, da evolução da medicina regenerativa e dos obstáculos e contradições com que se enfrenta sua organização global. Oferece-se uma revisão analítica da literatura internacional, que busca responder às seguintes perguntas: quais são as trajetórias principais de inovação em ciência e saúde nessa área? Quais fatores incidem na sua evolução? E, quais consequências eles trazem para a Saúde Coletiva? Analisam-se dados estatísticos em nível internacional, informaçoos qualitativas em arquivos das instituições de regulamentação globais, resenhas jornalísticas e artigos especializados em revistas indexadas.

Primeiro, se definem os tipos de células em uso nas pesquisas em estudo e a evolução histórica, científica e técnica do setor, para logo sintetizar de forma empírica as principais tendências na dinâmica global da PCT e descrever o estágio atual na formação do mercado global da medicina regenerativa. Conclui-se o artigo com uma breve reflexão sobre os desafios que a área traz para a Saúde Coletiva.

\section{Tendências científicas e econômicas na PCT global}

\section{Evolução histórica}

As células-tronco (CT), capazes de gerar cópias idênticas de si mesmas e se diferenciar nos tecidos que compõem o corpo humano, se aplicam principalmente nos transplantes, na reparação de tecidos doentes ou lesados. Mas elas são também utilizadas na pesquisa básica, em modelos para o estudo das doenças humanas ou para testar novas drogas e como vetores na terapia gênica (REHEN, 2007).

Essas células se classificam em dois tipos principais: pluripotentes, como as células-tronco embrionárias (CTE) - apenas encontradas nos embriōes nas fases iniciais da divisão celular, capazes de se diferenciar em qualquer tecido do 
corpo; e multipotentes, como as células-tronco adultas (CTA), com capacidade

de diferenciação apenas nos tipos celulares específicos dos tecidos de origem. Em 2007, se identificaram combinaçóes de genes que, quando ativados e transferidos, são capazes de transformar células somáticas em células de pluripotência induzida, chamadas de iPS (TAKAHASHI et al., 2007).

$\mathrm{O}$ primeiro transplante bem-sucedido utilizando células-tronco adultas (CTA) da medula óssea se realizou em 1968, no tratamento de dois irmãos com uma severa imunodeficiência combinada. Essas terapias começaram a se expandir na década de 2000 (UKCSI, 2005), constituindo, hoje, protocolos habituais nos sistemas de saúde pública. As CTA são utilizadas também na reparação de córneas, cartilagem e tecidos da pele.

O sangue do cordão umbilical e da placenta é outra fonte de CTA. O interesse clínico nessas células - descobertas em 1978 - se expandiu desde 1988, frente ao sucesso de um transplante para o tratamento da anemia de Fanconi. Até 2007, já tinham sido realizados 6.000 transplantes com esse tipo de sangue (MOISE, 2005), e se estimava um total entre 150.000 e 200.000 unidades do sangue armazenadas em bancos públicos internacionais (STEINBROOK, 2004).

Os bancos privados desenvolvem um marketing pouco rigoroso e costumam oferecer informações distorcidas sobre as vantagens da armazenagem desse sangue - que representa $25 \%$ do sangue armazenado em nível global. Estudos recentes têm mostrado que, nos transplantes autólogos, o sangue é utilizável apenas em três doenças - no blastoma neuronal e da retina e na anemia (EGE, 2004) - e aplicáveis apenas para um peso máximo do corpo de 50 a $55 \mathrm{~kg}$, com escassos índices de sucesso nos transplantes - de um em 20.000 casos (BROWN; KRAFT, 2006). Apesar do desenvolvimento de algumas campanhas de divulgação pública nos países avançados, a opinião pública internacional ainda não se encontra suficientemente bem informada sobre essa situação (GUNNING, 2004).

As CTE humanas foram desenvolvidas de duas fontes diferentes, em período semelhante. Em 1998, o cientista James Thomson, da Universidade de Wisconsin, nos EUA, isolou células da massa interna de blastocistos - embriōes até o quinto dia da gestação - e desenvolveu as primeiras cinco linhagens de CTE (THOMSON et al., 1998). No mesmo ano, o cientista Paul Gearhart e sua equipe da Universidade Johns Hopkins cultivaram pela primeira vez células germinativas humanas de células fetais do tecido das gônadas de fetos abortados 
(GEARHART, 1998). O desenvolvimento da fertilização assistida e da técnica de SNCT - substituição de núcleo celular de uma célula somática adulta e sua inserção numa CTE - ou clonagem terapêutica, utilizada na clonagem da ovelha Dolly, foram duas precondições na derivação das linhagens de CTE.

Mas o uso desse tipo de células suscitou grandes controvérsias sociais e debates públicos em nível global (ACERO, 2011b; PARRY, 2003), que resultaram em diferentes opções de regulamentação segundo as "epistemologias cívicas" de cada nação (JASANOFF, 2005) e em relação à caracterização ontológica e cultural específica das novas entidades biológicas (FRANKLIN, 1999; PARRY, 2010). As normativas regulatórias nacionais costumam variar segundo os tipos de embriōes e linhagens permitidos para pesquisa. Por exemplo, apenas os embriões extras da fertilização assistida, ou também a criação de embriōes específicos; linhagens de células apenas humanas ou também "cíbridas" (animal/humanos) (ISASI; KNOPPER, 2006; DINIZ; AVELINO, 2009).

O Reino Unido tem adotado as políticas mais liberais em PCTE, sendo pioneiro em permitir o uso de linhagens de CTE em pesquisa derivadas de diferentes fontes, seguido da Bélgica e da Suécia, com uma liberalização gradual das pesquisas desde a década de 2000, e dos países asiáticos emergentes como China, Coreia do Sul, Cingapura e, mais recentemente, Índia (WALTERS, 2004). No caso dos EUA, a situação mudou a partir do início do primeiro mandato do Presidente Obama, em 2009. Passou-se, no setor público, de uma opção de pesquisa apenas com linhagens de CTE já existentes, a outra que aceita quase todas as opções de fontes de derivação - exceto o uso da técnica de clonagem terapêutica (ACERO, 2011b). Em resumo, os avanços científicos têm se dirigido à procura sistemática de novas fontes de células-tronco e à diversificação de inovaçôes na terapia celular, sendo o uso das linhagens de iPS uma das apostas mais recentes e promissoras na área.

\section{Expansão atual}

O progresso em PCT global é rápido, com mais 2.000 artigos de pesquisa publicados por ano em revistas científicas internacionais. Autores dos EUA foram responsáveis por cerca de 6.000 publicações até o ano de 2009, concentradas na classificação de mais alta qualidade (MCMAHON et al., 2010). Em seguida, 
encontra-se Alemanha, com aproximadamente 1.700 publicações e, logo depois, Japão, Reino Unido e China, com 1.200 a 1.400 publicações cada um. Em contraste, no Canadá, Austrália, Brasil e Índia, elas variam entre 200 e 600 artigos e classificam-se num índice de menor qualidade.

Na PCT destacam-se os EUA, principal liderança global, e o Reino Unido, pioneiro no desenvolvimento científico e no desenho de regulamentação de referência internacional. Entre 2002 e 2007, por exemplo, os EUA destinaram 1.173,8 milhões de dólares americanos à PCT humana e 174,2 milhões de dólares americanos à PCTE (GOTTWEISS et al., 2009).

Na nova estratégia pública desenvolvida para a medicina regenerativa no Reino Unido, para o período 2006-2015, se estimava um investimento total de mais de 400 milhões de dólares dos EUA (DEPARTMENT OF HEALTH, 2011). Por exemplo, em 2010, o Conselho de Pesquisa Médica (MRC) foi responsável por $52 \%$ do financiamento do total de 353 projetos públicos em medicina regenerativa, correspondente a 112,5 milhões de dólares dos EUA do investimento total pelos quatro conselhos nacionais de pesquisa (MRC, 2012). Os conselhos definem também normativas sobre as práticas de excelência - técnica e ética que influem significativamente nas posições legislativas (MCR, 2011). Por outro lado, as associações filantrópicas - articuladas na Association of Medical Research Charities (AMRC) - investiram nessa área, no período 2005-2009, cerca de 42 milhões de dólares dos EUA (DEPARTMENT OF HEALTH, 2011).

Nos EUA, tinham sido registradas no Banco Nacional de Células-Tronco do Instituto Nacional de Saúde (NIH), até 2011, 136 linhagens de CTE para pesquisa (GOTTWEISS et al., 2009). Na Europa, por outro lado, teriam sido derivadas - até o mês de novembro de 2011, 332 linhagens de CTE, desenvolvidas por 85 grupos de pesquisa, concentrados no Reino Unido (109 linhagens e 20 grupos) e seguido pela Suécia (71 linhagens e 6 grupos). No Registro Europeu de Linhagens de CTE (hESCreg), a produção europeia, junto a de outros países fora da região, concentra cerca de 650 linhagens de CTE, que são utilizadas tanto para diagnósticos de medicamentos, como em pesquisa básica, pré-clínica e clínica em nível global.

Foi primeiro necessário desenvolver uma padronização global dos parâmetros científicos e técnicos das células e linhagens de CTE, para conseguir tanto uma qualidade nas linhagens como para possibilitar a colaboração internacional. Em 

(ISCI), organizada através do Foro Internacional de Células-Tronco (ISCF) do Reino Unido e integrada por agências e laboratórios na Europa, EUA, China, Japão e Austrália. O objetivo principal da ICSI foi definir, entre 30 laboratórios de liderança mundial, uma agenda de critérios estandardizados para derivação, caracterização e manutenção das linhagens de CTE.

A iniciativa se realizou em duas fases. Entre 2003 e 2005, se caracterizaram as origens, propriedades e condições de cultura de 75 linhagens de CTE (ANDREWS et al., 2005). Na segunda fase, partir de 2007, se acordou um meio de cultura comum às equipes para o cultivo das células, já que este influi em sua qualidade. Contudo, a grande diversidade de práticas e linhagens nos laboratórios dificultou chegar a um consenso sobre os temas. O ICSI criou um Registro Internacional de Linhagens de CTE, publicou as características de 59 linhagens de CTE em uso em 17 laboratórios e planejou seu uso coletivo e também dos dados (ISCI, 2007). Desse modo, tentou contribuir para diminuir e/ou gerenciar eventuais disputas no interior da rede, cumprindo papel muito importante na governança global da área.

No início da década de 2000, os diferentes países começam a estabelecer bancos de células e linhagens. O pioneiro foi o do Reino Unido, em 2004, seguido no ano seguinte pela Espanha; e a partir de 2009, pela Austrália, Índia, Cingapura, EUA, Suécia; e,em 2011, pela China. Muitos dos bancos funcionam em redes transnacionais e informam aos registros internacionais.

Segundo estimativas baseadas em dados da Plataforma Internacional de Registro de Ensaios Clínicos (ICTRP) da Organização Mundial da Saúde (OMS), havia um total global de 2.384 ensaios clínicos, em terapia celular, registrados até 15 de junho de 2009 (ISASI, 2009). Em janeiro de 2011, os ensaios registrados na base de dados do NIH dos EUA já representavam um total global de 3.363 (PETERSEN; SEEAR, 2011), e cerca da metade deles estava examinando eficácia e efetividade clínica (MASON; MAZZOTTI, 2010).

A grande maioria dos ensaios concentra-se nos EUA e se baseia em CTA. Até 2011, havia apenas quatro ensaios clínicos multicêntricos com CTE humanas em andamento - fases I e II - que incluem medicamentos e terapias celulares para lesões e atrofia na medula espinhal, para distrofia macular e na degeneração macular por envelhecimento. 
O ensaio pioneiro em PCTE foi desenvolvido pela empresa privada Geron e financiado pelo Instituto de Medicina Regenerativa da Califórnia (CIRM) para o teste da droga GRNOPC1, para lesões da medula espinhal, até 14 dias após a lesão. Mas, quase um ano depois, o recrutamento de pacientes foi interrompido, segundo a empresa, por problemas financeiros somados à falta de resultados promissores (GERON, 2009). A empresa privada Neural Stem Inc., dos EUA, iniciou um novo ensaio clínico com CTE em janeiro 2013, para lesões crônicas na medula espinal. Os outros dois ensaios com CTE são multicêntricos e desenvolvidos pela empresa privada Advanced Cell Technologies, para avaliar terapias celulares para lesões oculares.

Além disso, em julho de 2013, Japão autorizou os primeiros testes clínicos com iPS para tratar pacientes com degeneração macular (REVISTA VEJA, 2013). No mesmo mês, um fígado humano funcional foi criado in vitro a partir de iPS por outra equipe japonesa - um dos resultados mais promissores recentes nesta área (TAKEBE, 2013). Estima-se que em sete a 10 anos, poderão começar os ensaios clínicos em seres humanos com órgãos produzidos in vitro.

Apesar da evolução científica considerável na área e nos ensaios clínicos em terapia celular, esse aspecto é ainda hoje um dos menos regulados, padronizados e transparentes em nível global. Além dos ensaios clínicos aprovados por instituições competentes, há uma série de outras terapias celulares experimentais, em geral oferecidas como comprovadas a pacientes envolvidos no turismo médico internacional. Estima-se que, em 2012, haveria 700 clínicas operando nessa modalidade, na Ásia, Europa e América do Norte, e algumas delas localizadas também no México, Argentina e Costa Rica (EINSENDEL; ADAMSON, 2012). A falta de regulamentação transnacional em relação aos ensaios clínicos e ao turismo médico incide na qualidade da inovação no setor.

\section{A Propriedade Intelectual}

A regulação do sistema de direitos de propriedade intelectual (PI) é fundamental para a expansão do novo mercado global em medicina regenerativa. Coexistem três aproximaçôes bem diferentes, contraditórias e até antagônicas em relação aos direitos de proteção das CTE: as linhagens e produtos derivados. As práticas normativas e regulatórias diferem nos EUA e na União Europeia, e há ainda grupos específicos que propõem alternativas. 
As patentes de materiais biológicos nos EUA têm como precedente a decisão da Suprema Corte Americana de 1980 no caso Diamond vs. Chakrabarty, que outorgou uma patente a uma bactéria geneticamente modificada, abrindo caminho para a aprovação de patentes dos resultados de pesquisa básica na área e em outras associadas. Em 1980, pelo Bayh-Dole Act, permitiu-se que as universidades públicas, em parceria com empresas privadas, obtivessem patentes dos resultados de pesquisa básica apoiada com financiamento público.

A tendência à ampliação dos direitos de PI nos EUA transformou um dos sentidos iniciais desse sistema: o fomento à inovação. Mediante novas regras, os níveis de exigência para a verificação de "novidade e atividade inventiva" foram consideravelmente rebaixados e aumentou o escopo das "descobertas" que podem ser sujeitas a patentes, incluindo células, tecidos e genes humanos (ORSI; CORIAT, 2006). Os titulares das patentes também começaram a ter a exclusividade não apenas da inovação protegida, mas também de suas diversas aplicações.

Esse processo prejudicou o acesso às linhagens de CTE para pesquisa pela comunidade científica global, devido à aplicação de patentes high-wall ou patentes restritivas ou amplas (LEVINE, 2011). Por exemplo, as patentes pioneiras depositadas por James Thomson e seu grupo, Wisconsin Alumni Research Foundation (WARF), compreendem o método de isolamento de CTE de primatas e seres humanos, e três linhagens de CTE (de neurônios, do coração e de células das ilhas pancreáticas). Outra patente protege todas as linhagens de CTE das camadas embrionárias humanas: mesodérmica, endodérmica e ectodérmica, dando à WARF o direito virtual a todas as linhagens de CTE existentes.

Em 2002, a WARF outorgou à empresa Geron direitos exclusivos para desenvolver diagnósticos e terapias baseados nesses três tipos de linhagens. A empresa estabeleceu acordos para limitar o escopo de uso das linhagens de CTE em pesquisa e dos materiais biológicos compartilhados, o que elevou o custo das licenças - por exemplo, em 2005, este compreendia um pagamento inicial de 100.000 dólares dos EUA por linhagem e de mais 25.000 dólares por ano (MURRAY, 2007). Em 2006, e devido à forte pressão da comunidade científica e do governo, a Geron fixou um custo de 500 dólares por licença, aplicável a cada uma das linhagens de CTE para as pesquisas da rede do NIH.

No mesmo ano, as patentes do WARF foram contestadas por uma coalizão de cientistas e ativistas do país, após o qual o WARF modificou um pouco as 
características das licenças e abaixou seus preços. Mas o Escritório de Patentes e Marcas dos EUA (USPTO), em 2007, revogou as patentes; ainda assim, na frente da apelação do WARF, em 2008, a revogação se reverteu (ACERO, 2011 b). O exemplo ilustra as grandes dificuldades que se enfrentam no acesso as linhagens de CTE para pesquisa, assim como as incertezas envolvidas nas repetidas negociações institucionais, inclusive na distribuição de linhagens dentro da rede pública do NIH (NIH, 2006).

O sistema de PI permitiu que o USPTO, até o ano de 2006, tenha aprovado 41 patentes com CTE, concentradas na WARF e na empresa Geron, que controlam assim a raiz de toda possível diferenciação das CTE (BERGMAN; GRAFF, 2007). Isto tem gerado muita oposição dos cientistas americanos que reclamam pela diminuição do ritmo e das possibilidades em suas pesquisas, enquanto resultado direto do efeito dessas patentes (STEM..., 2007).

Em contraste, na Europa, há dois acordos regionais que regulamentam as patentes neste campo: a Convenção Europeia de Patentes do Parlamento e do Conselho da Europa, de 1973 (EPC, 1973), revisada em 2000 e 2007, e a Diretiva Europeia da Comissão Europeia sobre a proteção legal das invenções biotecnológicas, de 1998 (EC, 1988), que retoma princípios da primeira. A Convenção foi integrada à regulamentação do Escritório Europeu de Patentes (EPO) em 2000, e com uma exclusão das patentes em: (a) processos de clonagem de seres humanos; (b) modificações na identidade genética dos seres humanos na linha germinal; (c) uso de embriōes humanos com propósitos industriais e comerciais; e (d) modificação da identidade genética de animais e dos animais que resultam desses processos.

Nos debates públicos, os opositores têm invocado o princípio da "ofensa à moral" e da "ordem pública” para contestar os depósitos de patentes de materiais biológicos humanos na Europa. No caso das patentes de genes humanos, por exemplo, se manifestaram contra 14 opositores e os governos da Itália e da Holanda; e em 2002, seus argumentos foram aceitos pela EPO, mas a decisão foi apelada pela Universidade de Edimburgo e ainda está pendente uma resolução final.

Contudo, esse evento criou um precedente, e os primeiros intentos de depósito de patentes das CTE não modificadas da WARF e da Geron na Europa foram negados - com argumentos de aplicação eventual a outros 200 depósitos de patentes. Até o ano de 2006, a EPO não tinha aprovado nenhuma patente com o uso direto ou apresentando menção às CTE (PORTER et al., 2006). 
Em outubro de 2011, a Corte Europeia de Justiça colocou fim a um caso legal, e de longo prazo, apresentado pelo Greenpeace, contra uma patente de um método para gerar neurônios derivados das CTE de 1997. A Corte Europeia se manifestou sobre três pontos ambíguos na Diretiva Europeia de 1998: (a) a definição de embriāo humano; (b) se uma patente depositada para fins de pesquisa científica é relacionada a propósitos industriais e comerciais; e (c) se os procedimentos que utilizam CTE são elegíveis para patentes (CJE, 2011).

A Corte considerou que todo óvulo fertilizado deve ser considerado embrião humano, sempre que a fertilização inicie o processo de desenvolvimento de um ser humano, e ainda, nos casos onde a divisão celular tenha sido estimulada por partenogênese. Argumentou que o uso de embriōes humanos para fins de pesquisa científica, uso industrial e comercial devem ser excluídos das patentes. Além disso, declarou que também devem ser proibidos de patenteamento os processos que demandem a destruição de embrióes humanos ou sua utilização como materiais de base para a criação de alguma célula derivada. A decisão da Corte motivou a oposição de alguns dos especialistas e agentes de política pública europeia relevantes, com base no argumento de que pode se tornar um grande obstáculo ao desenvolvimento futuro das terapias celulares (ABBOTT, 2011).

Além disso, os opositores mais radicais- cientistas, acadêmicos, ativistas e reguladores -têm se unido, em especial na Europa, contra as patentes das células, tecidos e genes humanos. Esses grupos se propõem a repensar o sistema de PI atual, que obstaculiza as pesquisas científicas e o avanço do conhecimento, além de encarecer os tratamentos em saúde e as medicinas associadas (PALOMBI, 2009). Diferentes perspectivas focam em diferenciar os níveis de restrições nas patentes - exclusividade ou não exclusividade (BOYLE, 2003) - ou em alguma alternativa de PI compartilhada. Nesse último caso, se propõe moldar o sistema nos new commons - a exemplo dos arranjos de propriedade coletiva - por referência aos commons iniciais (CORIAT, 2011). Eles eram os territórios e instrumentos de propriedade comunitária e de livre acesso à população na Europa medieval, anteriores ao seu fechamento no início do capitalismo industrial. Mas inexiste ainda uma operacionalização prática e substantiva desses argumentos críticos.

O breve resumo apresentado sinaliza que o tema das patentes na área gera posições muito desencontradas, dentro e fora da comunidade científica internacional e entre regiōes geográficas. Ele carece de uma verdadeira resolução 
harmonizada em nível internacional, com casos legais sendo apresentados

regularmente à EPO e aos escritórios nacionais de patentes, muitos deles sendo arquivados por tempos prolongados e ainda aguardando resolução. Há também algumas indicações da forma como o sistema de PI retarda o avanço da ciência e, por vezes, obstaculiza processos eventuais de inovação em saúde.

\section{A formação do mercado em medicina regenerativa}

A medicina regenerativa constitui uma mudança do paradigma médico convencional para um novo paradigma, que procura a regeneração do organismo em nível celular ou tecidual (MASON; DUNNILL, 2008, p. 3). Ela compreende um total de quatro modalidades terapêuticas regenerativas diferentes: as terapias celulares com células somáticas ou maduras - que se baseiam em métodos farmacológicos convencionais; e as terapias com CTA, CTE e iPS.

Esta nova medicina enfrenta importantes desafios na transformação das plataformas tecnológicas industriais convencionais atuais, devido aos riscos clínicos, industriais e comerciais específicos e associados à utilização de materiais biológicos in vivo. Por exemplo, nas terapias autólogas, há altos riscos de contaminação cruzada no cultivo das células de diferentes pacientes; e, na manufatura de produtos alógenos, se requer mudar as formas convencionais de controle de qualidade e aplicar novas medidas de descontaminação através de todo o processo de manufatura (MASON; MANZOTTI, 2010).

O setor como um todo se encontra na fase da translação de resultados da pesquisa básica à clínica ou - no caso das CTE e das iPS - ainda nos primeiros momentos dos ensaios clínicos das terapias celulares. Ainda que a maioria das terapias celulares comerciais hoje tenha base apenas em células somáticas - desenvolvidas com métodos convencionais, como no caso da pele artificial Apligraf - uma geração de terapias em CTA está começando a surgir. Por exemplo, quase mil pacientes já têm sido tratados para lesões nas córneas, em países como Itália, Índia e China (MASON, 2009).

Os dados estatísticos sobre a expansão global do setor privado diferem bastante, segundo as fontes consultadas e pela definição diferencial dos subsetores incluídos na avaliação - por exemplo, produtos, serviços, tecnologias de apoio e culturas e terapias com diferentes tipos de células e para doenças variadas. $\mathrm{Ou}$ 
seja, os dados a seguir devem ser considerados apenas como proxy de tendências e até que o setor em formação demarque melhor suas fronteiras.

Um relatório da BioPhenix (2006) - uma consultoria da área de biomedicina na Inglaterra - identifica um total de 106 empresas atuando na área de célulastronco (CT) em nível global, mas apenas 11 delas estariam focadas em PCTE. Em 2007, outros autores calculavam a existência de um total de 91 empresas privadas, com $61 \%$ delas atuando em CTA, 27\% em sangue do cordão e 12\% em CTE. Dentre essas firmas, 41 desenvolveriam pesquisa pré-clínica; 25, ensaios clínicos; e 25, comercialização (LYSAGHT et al., 2008).

Os EUA, em 2009, controlavam 60\% do mercado global de CT, em geral concentrado nos transplantes do sangue da medula óssea. As principais empresas - "players" em nível global - são também de origem americana, muitas baseadas na Califórnia. Existiam, nesse mesmo ano, 28 empresas em medicina regenerativa no Reino Unido, a maioria delas spin-offs das principais Universidades, e uma delas - StemCells for Safer Medicines (SC4SM) - em parceria entre o Governo, a academia e a indústria. As empresas dedicadas ao diagnóstico de droga sIntercyte e Stem Cell Sciences (SCS) - já contavam com financiamento da indústria farmacêutica (PERRIN, 2005).

No início do desenvolvimento da PCT, a tendência das grandes empresas farmacêuticas era de se abster de investir no setor, o que prejudicou a disponibilidade de capital financeiro, as possibilidades de expansão de infraestrutura e o aproveitamento da sua experiência em ensaios clínicos de grande porte. Mas na metade da década de 2000, essa situação começou a se reverter. $\mathrm{O}$ fator que mais parece ter contribuído para essa mudança foi o sucesso comercial da empresa Dendreon, com sua vacina celular autóloga para câncer da próstata, Provenge®(LICHTENBERG, 2011) - e também o desenho de modelos de doença com CT para o teste virtual de drogas e medicamentos.

Um estudo de Wall Street sobre as grandes empresas farmacêuticas detectou vários programas envolvendo CT (REGLADO, 2005). Por exemplo, Merck, Sharpe \& Dohme desenvolve terapias e medicamentos para a regeneração de neurônios, com base em derivados de CTA e de CT fetais, para acidente vascular cerebral (AVC) e na doença de Alzheimer; Johnson \& Johnson investiu na empresa Novocell Inc. da Califórnia, em relação à produção com CT de insulina 
para diabetes tipo 1; e a Novartis AG, a GSK e a Pfizer desenvolvem, entre outras, terapias celulares para doenças cardíacas.

Em resumo, há em formação um novo mercado em saúde global, a partir da expansão das aplicações medicinais e terapêuticas das células somáticas e das CT. Mas ele enfrenta vários obstáculos e indefinições: a regulamentação em relação à inclusão do capital privado e de risco no setor e aos ensaios clínicos - sua visibilidade e transparência; a determinação das prioridades de investimento e pesquisa das grandes empresas farmacêuticas; níveis de riscos ainda imprevisíveis nos produtos desenvolvidos e eventuais, assim como as grandes contradições "idas e vindas regulatórias" - em relação aos direitos de propriedade intelectual. A combinação desses fatores não apenas incide significativamente na direção da inovação em saúde e na expansão do mercado, mas também se reflete significativamente na Saúde Coletiva.

\section{Desafios para a Saúde Coletiva}

Podemos caracterizar vários tipos de desafios desta área em relação à Saúde Coletiva. Primeiro, a nova medicina se depara com diferenças nos níveis de aceitação e familiaridade das diferentes comunidades e países sobre as características destes produtos e terapias; sobre as incertezas técnicas e éticas envolvidas, e socialmente aceitáveis; sobre os níveis de eficácia e eficiência previsíveis vis-à-vis outras alternativas terapêuticas e os "desconhecidos" na ação terapêutica no médio e longo prazo, em especial nos produtos e terapias eventuais com CTE e iPS.

Em segundo lugar, uma melhor aceitação social do novo referencial científico e médico requer um debate público, de maior visibilidade em assuntos específicos do diálogo e maior divulgação pública através da mídia, além de grande transparência nas práticas médicas nos consultórios privados e na política pública. A exclusão do público amplo, sua inclusão apenas seletiva e/ou a falta de políticas sistemáticas de engajamento público têm sido estratégias frequentes em muitos países (ACERO, 2011a) - exemplificadas no caso da armazenagem do sangue do cordão e da placenta em bancos privados. As políticas públicas deveriam se desenhar em diálogo amplo e com foco numa real compreensão social dos fatores sociopolíticos e biológicos envolvidos nos materiais e métodos utilizados na terapia celular. 
Terceiro, mostramos que há países que ficaram fora da padronização sócio-técnica inicial das principais linhagens de CTE desenvolvidas e, mais recentemente, das iPS - como reflexo das desigualdades internacionais em ciência e colaboração científica, e o papel de governança global excludente exercida pela ICSI. Esses processos geram impactos negativos na Saúde Coletiva, em especial das populaçôes nos países emergentes, ao se encarecer os preços dos materiais base para o desenvolvimento de novos medicamentos e terapias e/ou no caso de sua importação.

Quarto, ainda existem vazios importantes na harmonização internacional da regulação em pesquisa e medicina na área, por exemplo, no caso dos ensaios clínicos e dos sistemas de propriedade intelectual. Essa situação expõe as populaçôes, com destaque para as mais vulneráveis, a riscos extras e específicos: (a) sua exposição como sujeitos de experimentação em terapia, em situação desprotegida ousemiprotegida - incluídas as práticas médicas na "fronteira da ilegalidade", documentadas para a venda de óvulos para pesquisa e reprodução em mercados paralelos (WALDBY, 2008) e nas terapias celulares não comprovadas oferecidas a pacientes internacionais no turismo médico (PATRA; SLEEBOOMFAULKNER, 2009); (b) o uso ou eventual "despojo" de materiais biológicos dos próprios corpos dos pacientes, sem compensação monetária, na ausência de divisão simétrica ou compartilhada de benefícios, ou de forma coercitiva.

A falta de benefícios simétricos para a utilização comercial de tecidos doados ou "extraídos de fato", instala situações de injustiça social. Por exemplo, nas pesquisas e terapias baseadas em linhagens de células imortais, o uso primário em pesquisa e, em especial, o uso secundário em pesquisa e/ou comercial de tecidos, pode vir a acontecer através de períodos muito prolongados de tempo. Por um lado, há bastante desinformação pública sobre as possibilidades de compensações ou benefícios compartilhados; por outro, grandes dificuldades no desenho de instrumentos adequados para a operacionalização efetiva de formas alternativas na distribuição de benefícios - entre diferentes tipos de participantes em pesquisa e terapia: pesquisadores/clínicos, financiadores e pacientes. $\mathrm{O}$ assunto merece uma reflexão pública e sistematizada.

Vários casos emblemáticos de utilização de tecidos humanos sem aprovação prévia, em pesquisa, terapias e produtos associados, têm sido documentados na área. Destacam-se os casos dos tecidos do baço removidos de um paciente 
pela Universidade de Califórnia e eventualmente patenteados (Moore vs. the

Regent of California University, 1990) ${ }^{2}$ e do sangue do povo maori para pesquisa (DICKENSON, 2007). Mas é nosso entendimento que, em um sentido, o tema excede o mero consentimento livre e esclarecido do paciente no momento do ato científico e médico, uma vez que muitos indivíduos desconhecem a magnitude dos ganhos econômicos eventuais no uso desses materiais biológicos - a médio e longo prazos - e devido à ignorância e/ou incertezas sobre as potenciais interseções científicas, clínicas e comerciais envolvidas nesta área.

Como resultado desse conjunto de fatores, podem vir a se agravar os problemas de acesso público irrestrito às eventuais terapias/medicinas celulares, além de dificultada sua entrada no espaço da saúde pública, em especial nos países emergentes. Colocam-se questôes sociais, econômicas e éticas diferenciais no caso das terapias celulares autólogas versus as alógenas. As primeiras, "customizadas ao cliente", envolvem capacidades médicas especializadas, assim como custos maiores, e reformulação ou distanciamento da dimensão coletiva da saúde. As segundas, potencialmente de uso maciço, ainda dependem da existência de uma plataforma tecnológica e manufatura industrial, de sistemas de transporte, de infraestrutura e manipulação hospitalar, construídas com base em novos parâmetros de segurança e descontaminação.

Finalmente, apresenta-se como imperativa a necessidade de desenvolver consciência pública, negociações adequadas - via organizações internacionais e acordos bilaterais - e novas ações políticas e legais, para instalar formas de governança e regulamentação transnacionais sobre o turismo médico em terapia celular experimental e na venda associada de óvulos para pesquisa e reprodução - práticas decorrentes das zonas cinzas na interseção entre as políticas em ciência e em saúde.

\section{Referências}

ABBOT, A. German science organizations slam European court over stem-cell ruling. Nature. Disponível em: http://www.nature.com/news/german-science-organizations-slameuropean-court-over-stem-cell-ruling-1.9606. Acesso em: 16 jul.2014.

ACERO, L. Pesquisas e terapias com células-tronco: Governança, visōes sociais e o debate no Brasil. Rio de Janeiro: E-Papers, 2011a. 
ACERO, L. Governança na nova genética e a participação pública: o caso das pesquisas com células-tronco. Physis: Revista de Saúde Coletiva, v. 21, n. 3, p. 795-812, 2011 b.

ANDREWS, P. et al. The International Initiative on Stem Cell Research: towards benchmarks for human embryonic stem cell research. Nature Biotechnology, v. 23, n. 7, p. 795-797, 2005.

BERGMAN, K.; GRAFF, G.D. The global stem cell patent landscape implications for efficient technology transfer and commercial development. Nature Biotechnology, v. 25, p. 419-24, 2007.

BIOPHOENIX. Opportunities in stem cell research and commercialization: technology advances, regulatory impact and key players. Coventry: Biophoenix, 2006.

BOYLE, J. The Second Enclosure Movement and the construction of the public domain. Law and Contemporary Problems, v. 66, n. 1/2, p. 33-74, 2003.

BROWN, N.; KRAFT, A. Blood ties: banking the stem cell promise. Technology Analysis \& Strategic Management, v. 18, n. 3/4, p. 313-327, 2006.

CORIAT, B. La crise de l'idéologie propriétaire et le retour des communs . Contretemps 2011. Disponível em: <www.contretemps.eu>. Acesso em: 28 maio 2013.

COURT OF JUSTICE OF THE EUROPEAN UNION. Press Release $n^{o}$ 112/11, 2011. Disponível em: <www.curia.europa.eu/jcms/upload/docs/ application/pdf/2011-10/ cp110112en.pdf>.Acesso em: 14 out. 2013.

DEPARTMENT OF HEALTH. Taking stock of regenerative medicine in the United Kingdom. Department for Business, Innovation \&Skills, Office for Life Sciences. London: Dept. of Health, 2011.

DICKENSON, D. Property in the body: feminist perspectives. Cambridge: Law, Medicine and Ethics, Cambridge University Press, 2007. 208p.

DINIZ, D., AVELINO, D. Escenario internacional de la investigación em células madre embrionárias. Revista de Saúde Pública, v. 43, n.3, 2009.

EUROPEAN COMMISSION. On the legal protection of biotechnological inventions. Directive 98/44/EC of the European Parliament and of the Council. Official Journal, L 213, p. 0013-0021, 30 jul 1998.

EUROPEAN GROUP ON ETHICS, SCIENCE AND NEW TECHNOLOGIES. Ethical aspects of Stem Cell Research, Opinion $n^{\circ}$ 15, European Group on Ethics in Science and New Technologies. Brussels: European Commission, 2004.

EUROPEAN PARLIAMENT and COUNCIL.Convention on the Grant of European Patents, 5 Out. 1973. Disponível em:www.epo.org/law-practice/legal texts/html/ epc/1973/e/contents.html. Acesso em: 15 out. 2013. 
EINSENDEL, E.F.; ADAMSON, H. Stem cell tourism and future stem cell tourists: policy and ethical implications. Developing World Bioethics, v. 12, n. 1, p. 35-44, 2012.

FRANKLIN, S. Making representations: the parliamentary debate on the Human Fertilization and Embryology Act. In: EDWARDS, J. et al. (Ed.). Technologies of Procreation: kinship in the age of assisted conception. London: Routledge, 1999. p. 14-28.

GEARHART, J. New potential for human embryonic stem cells. Science 6, v. 282, n. 5.391, p. 1.061-1.062, 1998.

GERON CORPORATION. World's first clinical trial of human embryonic stem cell therapy cleared. Regenerative Medicine, v. 4, n. 2, p. 161, 2009.

GUNNING, J.A. Worldwide study of umbilical cord blood banking. In: EUROPEAN COMMISSION. Annex to Opinion 19 of the European Group on Ethics in Science and New Technologies. Brussels: European Commission, 2004.

GOTTWEISS, H. Governing genomics in the 21st century: between risk and uncertainty. New Genetics and Society, v. 24, n. 2, p. 175-194, 2005.

GOTTWEISS, H.; SALTER, B.; WALDBY, C. The global politics of human embryonic stem cell science: regenerative medicine in transition. London: Palgrave, 2009.

INTERNATIONAL STEM CELL INITIATIVE. Characterization of human embryonic stem cell lines by the International Stem Cell Initiative. Nature Biotechnology, v. 25, p. 803816, 2007.

ISASI, R. Registration of stem cell-based clinical trials: a cientific and ethical imperative. World Stem Cell Report 2009. Florida: Genetics Policy Institute, 2009.

ISASI, R.; KNOPPER, B. Regulatory frameworks for Stem Cell Research. Human Reproduction, v. 2, n. 10, p. 2474-2481, 2006.

JASSANOFF, S. Design of nature: science and democracy in Europe and the United States. Princeton, NJ: Princeton University Press, 2005. 374p.

MARTIN, P.; BROWN, N.;TURNER, A. Capitalizing hope: the commercial development of umbilical cord blood stem cell banking. New Genetics and Society, v. 27, n. 2, p. 127-143, 2008.

MASON, C.; DUNNILL, P. A brief definition of regenerative medicine.Regenerative Medicine, v. 3, n. 1, p. 2-5, 2008.

MASON C.; MANZOTTI, E. Regenerative medicine cell therapies: numbers of units manufactured and patients treated between 1988 and 2010. Regenerative Medicine, v. 5, n. 3, p. 307-313, 2010.

MASON, C. et al. Cell therapy industry: billion dollar global business with unlimited potential. Regenerative Medicine, v. 6, n. 3, p. 265-272, 2011.

MCMAHON, D. et al. Regenerative medicine in Brazil: small but innovative. Regenerative Medicine, v. 5, n. 6, p. 863-876, 2010. 

MRC, 2012.

MEDICAL RESEARCH COUNCIL. Regenerative medicine forward look: stakeholder workshop. Report Summary on a Stakeholder Workshop, 5-6 September, Issue 1.2, London: MRC,BBSRC,ESRC, EPSRC, TSB, 2011.

MOISE, K. Umbilical cord stem cells. Obstetrics and Gynaecology, v. 106, n. 6, p. 13931407, 2005.

MURRAY, F. The stem-cell market: patents and the pursuit of scientific progress. New England Journal of Medicine, v. 356, p. 2341-3, 2007.

NATIONAL INSTITUTE OF HEALTH. Regenerative Medicine Report, Washington: NIH, 2006.

LEVINE, A. Access to human embryonic stem cell line. Nature Biotechnology, v. 29, p. 1.079-1.081, dez 2011.

LICHTENBERG, F. Despite steep costs, payments for new cancer drugs make economic sense. Nature Medicine, v. 17, n. 3, p. 244, 2011.

LYSAGHT M.J.; JAKLENEC, A.; DEWEERD, E. Great expectations: private sector activity in tissue engineering, regenerative medicine, and stem cell therapeutics. Tissue Engineering, v. 14, p. 302-315, 2008.

ORSI, F.; CORIAT, B. The new role and status of intellectual property rights in contemporary capitalism. Competition \& Change, v. 10, n. 2, p. 162-179, 2006.

PALOMBI, L. Gene cartels: biotech patents in the age of free trade. Melbourne: Scribe, 2009. PARRY, S. Interspecies entities and the politics of nature. In: PARRY, S.; DUPRÉ, J. (Eds.) Nature After The Genome. Oxford: Blackwell, 2010. p. 25-34.

PARRY, S. The politics of cloning: mapping the rhetorical convergence of embryos and stem cells in parliamentary debates. New Genetics and Society, v. 22, n. 1, p. 77-200, 2003.

PATRA, P.K.; SLEEBOOM-FAULKNER, M. Recruiter-patients as ambiguous symbols of health: bionetworking and stem cell therapy in India. New Genetics and Society, v. 30, n. 2, p. 155-166, 2011.

PERRIN, N. The Global Commercialisation of UK Stem Cell Research. London: DTI, 2005. PETERSEN, A.; SEEAR, K. Technologies of hope: techniques of the online advertising of stem cell treatments. New Genetics and Society, v. 30, n. 4, p. 329-346, 2011.

PORTER, G. et al. The patentability of human embryonic stem cells in Europe. Nature Biotechnology, v. 24, p. 653-655, 2006.

PRAINSACK, B.; GEESINK, I.; FRANKLIN, S. Guest introduction cell technologies 1998-2008: controversies and silences. Science as Culture, v. 17, n. 4, p. 351-362, 2008. 
REGLADO, A. Big companies quietly pursue research on embryonic stem cells. Wall Street Journal, 12 abr 2005.

REHEN, S. Células-tronco: o que são? Para que servem? São Paulo: Vieira e Lent, 2007.

REVISTA VEJA. Japão autoriza primeiros testes clínicos com células-tronco pluripotentes induzidas. 17 jul. 2013. Disponível em: www. veja.abril.com.br/noticia/ciencia/luz-verdeno-japao-para-testes-clinicos-com-celulas-tronco-ips. Acessoem: 10 set. 2013.

STEINBROOK, R. The cord blood controversies. New England Journal of Medicine, v. 351, n. 22, p. 2255-2257, 2004.

STEM CELLBUSINESS NEWS. Top stem cell scientists argue against Thomson/WARF Patents. Stem Cell Business News, 5 Jul. 2007.

TAKAHASHI, K. et al. Induction of pluripotent stem cells from adult human fibroblasts by defined factors. Cell, v. 131, n. 5, p. 861-872, 2007.

TAKEBE, T. et al. Vascularized and functional human liver from iPSC-derived organ bud transplant. Nature, v. 499, p. 481-484, 2013.

THOMSON, J.A. Embryonic stem cell lines derived from human blastocysts. Science, v. 282, n. 5391, p. 1145-1147, 1998.

UKSCI. Report and Recommendations. London: Department of Health, 2005.

WALDBY, C. Oocyte markets: women's reproductive work in ESCR. New Genetics and Society, v. 27, n. 1, p. 19-31, 2008.

WALTERS, L. Human embryonic stem cell research: an intercultural perspective. Kennedy Institute of Ethics Journal, v. 14, n. 2, p. 34-55, 2004.

\section{Notas}

${ }^{1}$ Com esse termo, Jasanoff (2005, p. 127) define as múltiplas formas na qual o conhecimento é produzido, apresentado, testado, verificado e utilizado no domínio público; conhecimento que é contextual e histórico.

${ }^{2}$ Na seguinte sequência: em 1976 foi extraído, no hospital da Universidade de Califórnia, o baço do paciente e seus tecidos foram utilizados em pesquisa sem consentimento prévio; em 1984, a Universidade obteve uma patente da linhagem celular Mo. Na atualidade, há nove produtos desenvolvidos sob licença pelo Genetics Institute e a empresa Sandoz Pharmaceuticals na base desses tecidos. Apenas em 1990, a decisão da Corte falou a favor da PI da Universidade e contra os interesses e a compensação demandada pelo paciente. 
International policies in science and health: cellular research and regenerative medicine Medicine and therapy developments based upon scientific principles of biosciences and health biotechnologies - with the use of live cells which are difficult to standardize - have been subject of wide public debates at the global level. The area has been recently defined as one of regenerative medicine that includes stem cell research and therapy, the focus of our study. This paper presents the main historical research events in cellular research, describes regenerative medicine's present stage of evolution and the characteristics of the main public policies developed, most especially in the leading countries and in relation to the regulation of intellectual property rights. A quantitative and qualitative analysis is developed, drawing upon different sets of secondary data collected internationally, bibliographic and archival information from global regulatory institutions, updated journal reviews as well as of specialized articles published in international journals. This information is reviewed guided by the following questions: which are the main trajectories in health innovation in this area? Which factors have most highly influenced its evolution? The paper concludes with reflections on the specific impacts of associated developments on collective health.

> Key words: regenerative medicine; stem cell research and therapy; collective health; health public policy; intellectual property rights. 